\title{
Field investigations on port non-tranquility caused by infra-gravity water waves
}

\author{
A. Najafi-Jilani and D. Rahimi-Maleki \\ Civil Engineering Department, Tarbiat Modares University, Tehran, Iran
}

\begin{abstract}
Field investigations have been carried out in two 60-day stages on the surf beat low frequency waves in Anzali port, one of the main commercial ports in Iran, located in southwest coast of the Caspian Sea. The characteristics of significant water waves were measured at three metering stations in the sea, one at the entrance of the port and three in the basin. The measured data were inspected to investigate the surf beat negative effects on the tranquility of the port. Using field measurements and complementary numerical modeling, the response of the basin to the infra-gravity long waves was inspected for a range of wave frequencies. It was concluded that the water surface fluctuations in the port is strongly related to the incident wave period. The long waves with periods of about $45 \mathrm{~s}$ were recognized as the worst cases for water surfaceperturbation in the port. For wave periods higher than the mentioned range, the order of fluctuation was generally low.
\end{abstract}

KEYWORDS: Surf beat; Infra-gravity waves; Port tranquility; Low frequency waves; Field investigations.

\section{INTRODUCTION}

Penetration of surf beat into the berthing basins in harbors may have negative effects on the tranquility of the harbor (Mei and Agnon, 1989; Smallman and Cooper, 1989). In the basins of the ports, water surface oscillations can occur in response to the surf beat spectrum, responding to a specific range of wave periods. The responses to specific periods depend on the geometry of the basin and the periods of the spectrum that are active at the basin location. Based on the literature review, the investigations on the surf beat effects on the coastal area can be generally categorized as experimental studies and field investigations.

Firstly, experimental data were produced on the surf beat generation and propagation in various bottom boundary conditions. Some applicable experimental data on two dimensional surf beat generation had been produced recently by Baldock et al. (2000). A comparison between the generated laboratory data and the theoretical results obtained on the basis of Symonds et al. (1982) are in good agreement with each other. Low-frequency waves generated on a submerged curvilinear sill were experimentally studied by Dong et al. (2008). They used bi-chromatic wave groups with and without an opposing current in a laboratory flume.

Secondly, field measurements and observations were carried out to inspect the surf beat generation and propagation procedures. It had been shown based on field

Corresponding author: A. Najafi-Jilani

e-mail:a.jilani@modares.ac.ir measurements that the surface fluctuations in shallow water can be dominated by infra-gravity wave energy. The change of the coastal morphology may also be caused by these low frequency long waves (Osborne and Greenwood, 1992; O'Hare and Huntley, 1994; Ciriano et al. 2005, Smith and Mocke, 2002). Fujinawa (1979) presented field observation for long ocean waves with periods of one to several minutes at a marine observation tower. Based on the analysis of time series data and envelop of incident swell, Fujinawa (1979) proposed that the long forced waves are only a minor part of the surf beats. Holland et al. (1995) showed that the standing wave pattern due to reflection of the long waves can be generated by surf beat effects in water depths less than $4 \mathrm{~m}$. Herbers et al. (1995) presented field evidence of significant net cross shore surf beat propagation at water depths of $13 \mathrm{~m}$. Henderson and Bowen (2003) made field investigations on a barred beach at about $8 \mathrm{~m}$ water depth to study the crossshore propagation of surf beat and the associated cross shore flux of surf beat energy. The field measured data in the literature show the effect of low frequency wave's amplitude and period on the coastal areas, especially on the undesirable oscillations of water surface in the port basins. Literature shows that the generation and propagation procedures of the surf beat long waves have some uncertainties, requiring the need to investigate sites specifically using field observations. The negative effect of the surf beat on tranquility of harbors is one of the most important issues in the design or modification of the ports. The field measurements can be recognized as one of the best method to inspect the infra- 
gravity wave's effects on the harbors which have experienced the undesirable water surface fluctuations.

In this work, field investigations have been carried out on the surf beat low frequency waves in Anzali port, which is one of the main commercial navigation ports in Iran (Badiee, et al., 2004) and located at the southwest coasts of the Caspian Sea. Two 60-day stages of field investigations were conducted. The characteristics of significant water waves were measured at three metering stations in the sea, one at the mouth of the basin, and three in the basin. The measured data were used to investigate the surf beat effects on the water surface fluctuations. The water wave characteristics were determined based on the field measurements made using wave recorders. The comparison is made between incident short waves and infra-gravity long waves caused by breaking of incident waves. Based on the field measurements, the response of the basin to the long waves is inspected for various range of wave frequency. Complementary inspection is also made using well validated numerical model to determine the worst cases of undesirable water surface fluctuations in the berthing basin of the port.

\section{FIELD MEASUREMENTS}

Data were collected on the southwest coasts of Caspian Sea near to the Anzali port, one of the main navigational and commercial ports in northwest of Iran located at E $49^{\circ} 27^{\prime}$ $27^{\prime \prime}$ and $\mathrm{N} 38^{\circ} 27^{\prime} 27^{\prime \prime}$. Field measurements were carried out in an approximately $5 \mathrm{~km}^{2}$ area including the main berthing basin of the port and the seawater in front of the breakwaters. The measurements zone covered a maximum length of about $3.2 \mathrm{~km}$ along the coastline and about $1.5 \mathrm{~km}$ length along the cross-shore which extended to about $15 \mathrm{~m}$ water depth relative to mean sea level (MSL). Fig. 1 shows an overview of Anzali port at southwest of Caspian Sea and the general boundaries of study area. The water surface time series were measured to determine the significant wave height and period in the study area.

Seabed elevations were determined with surveys from an amphibious vehicle and sonar altimeters. The water surface fluctuations were measured at two 60-day stages. The first stage measurements were made during November 21, 2007 to January 19, 2008. The second stage measurements were conducted during April 21, 2008 to June 19, 2008. The water waves were measured at four directional wave metering stations (WD-1 to WD-4) located in the sea and three inbasin non-directional wave meters ( $\mathrm{WN}-1$ to $\mathrm{WN}-3$ ) located in the harbor as shown in Fig 2. The metering station WD-4 is located at the entrance of the basin. The exact installation location of the metering devices is listed in Table 1. Valeport metering devices were used to measure the directional and non-directional water waves in metering stations. Resonant silicon pressure transducer type sensors were used to measure the water surface elevation. The sensor had a water metering range of 0 to $130 \mathrm{~m}$ with a resolution of $\pm 0.001 \%$, and an accuracy of $\pm 0.01 \%$ of full scale. The direction of wave propagation in seaward stations is measured using gimbaled fluxgate compass covering a range of 0 to $360^{\circ}$ with $0.25^{\circ}$ resolution and $\pm 1^{\circ}$. Recording was done continuously for 30 minutes at every one hour interval in each station. The recorded data was downloaded from each device at one week intervals.

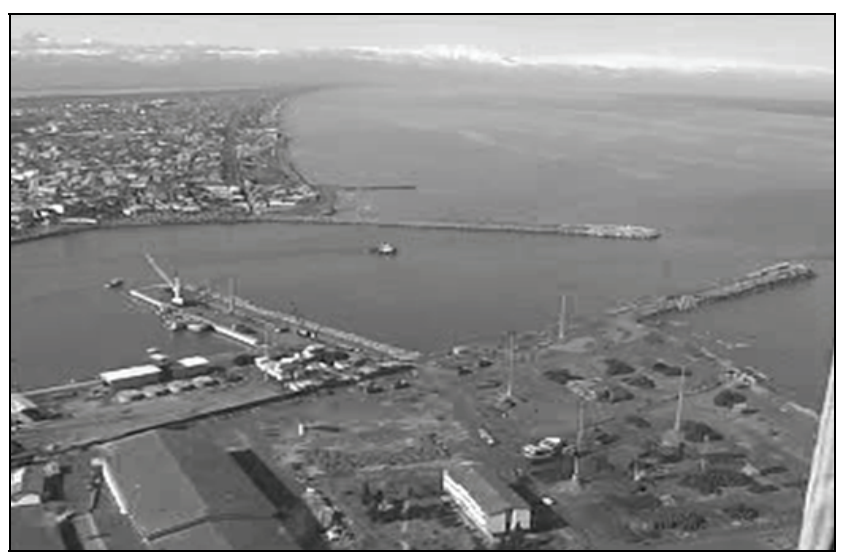

(a) Overview of Anzali port at southwest of Caspian Sea.

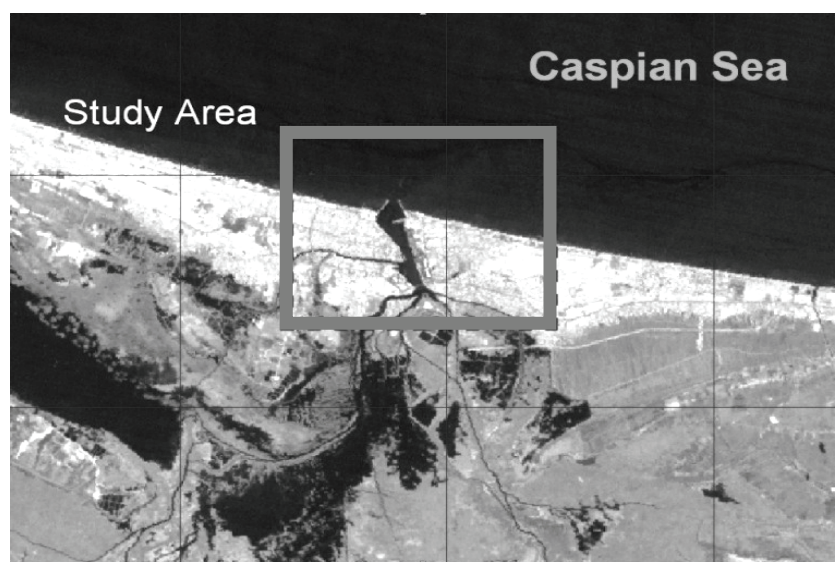

(b) Boundaries of study area.

Fig. 1 Overview of Anzali port and the boundaries of study area.

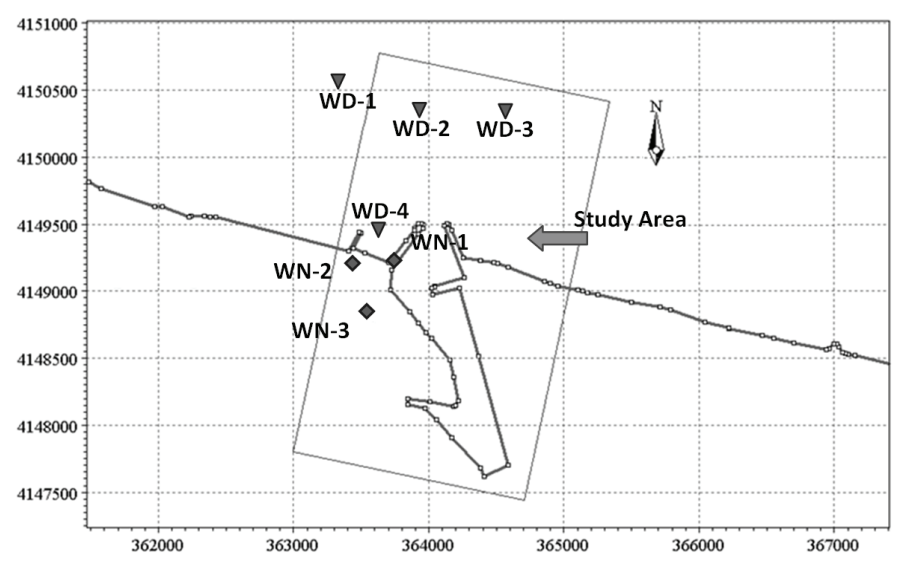

Fig. 2 Locations of water wave recording stations during field measurements, WD: directional and $\mathrm{WN}$ : non-directional water wave metering devices. 


\section{RESULTS AND DISCUSSION}

The wave heights measured at the wave recorders during the first stage of field measurements are presented in Table 2. As indicated in this table, in some stormy days, the incident wave height at the mouth of the port (at WD-4 wave metering station) exceeded $1 \mathrm{~m}$ height. More investigation on the wave characteristics can be made from the measured data presented in Fig. 3. In this figure, the characteristic wave heights measured at four metering stations WD-1 to WD-4 is presented. Fig. 3a, shows the time series plot of the measured wave heights. The storm condition and high-order incident waves occurred at three time periods at days 7-12, 25-31, and 46-57. The wave height at all of these periods at the entrance of port exceeds $1 \mathrm{~m}$. Based on detailed investigations on these stormy days, these high-order incident waves, which may cause the unrest condition in the port, can be categorized either as short waves or as long waves. The high-order waves of over $1 \mathrm{~m}$ height but with a period between 5 to 15 seconds can be classified as short waves and their values are indicated in italic in Table 2. The high-order waves with a period between 25 to 45 seconds can be classified as long waves. The measured wave characteristics in these days are indicated by bold values in the table.

Table1. Specifications of field measurements stations for water waves recording.

\begin{tabular}{|c|c|c|c|c|c|c|}
\hline \multirow{2}{*}{ Station } & Location & Parameter & Metering Device & \multicolumn{2}{|c|}{ Coordinates } & \multirow{2}{*}{ Water depth $(m)$} \\
\cline { 4 - 7 } & & & & E $(m)$ & N $(m)$ & \\
\hline WD-1 & Seaward & Directional Wave & Valeport, 730D & 363810 & 4150550 & 14.2 \\
\hline WD-2 & Seaward & Directional Wave & Valeport, 730D & 364350 & 4150240 & 13.1 \\
\hline WD-3 & Seaward & Directional Wave & Valeport, 730D & 364960 & 4150260 & 14.9 \\
\hline WD-4 & Port Entrance & Directional Wave & Valeport, 730D & 364050 & 4149450 & 5.5 \\
\hline WN-1 & In-Basin & Non-dir. wave & Valeport, 730W & 364150 & 4149230 & 4.7 \\
\hline WN-2 & In-Basin & Non-dir. wave & Valeport, 730W & 363880 & 4149220 & 4.8 \\
\hline
\end{tabular}

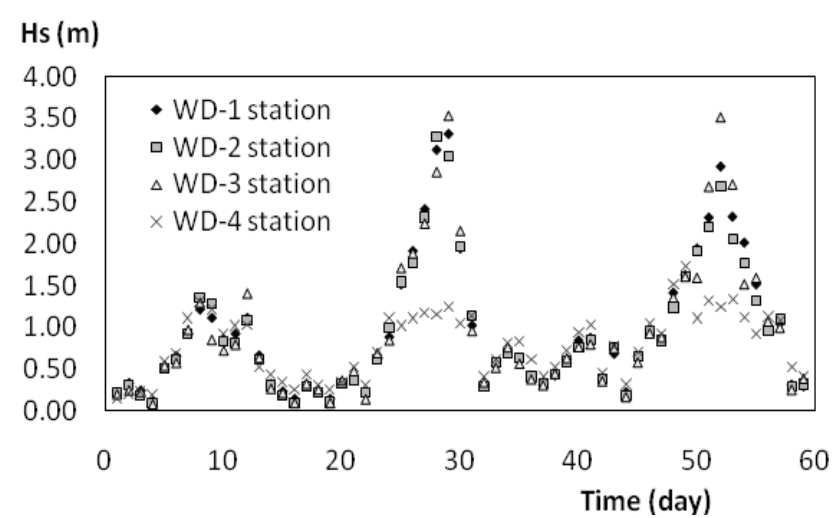

(a) Significant wave height (Hs).

Ts (s)

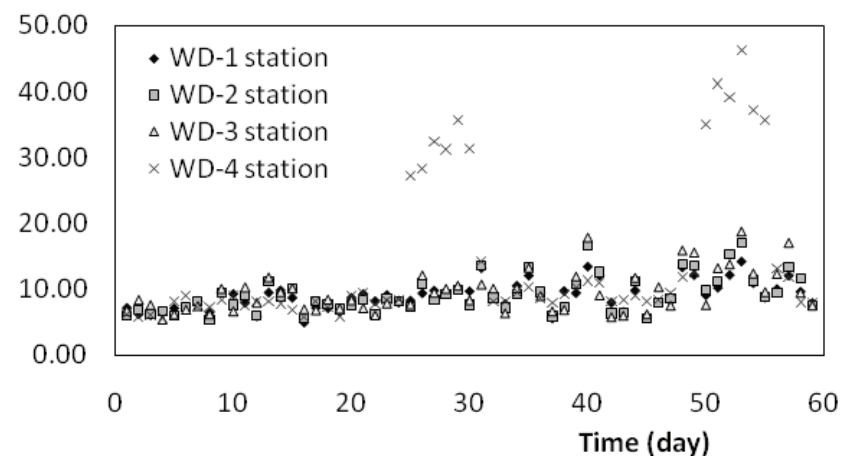

(b) Significant wave up-zero crossing period (Ts).

Fig. 3. Wave characteristics measured in seaward metering stations at $1^{\text {st }}$ stage field measurements.
Similar investigations can be made on the measured data in the second stage of field investigations. The main characteristics of measured wave at four stations WD-1 to WD-4 at the second stage of field measurements are listed in Table 3. The time series of measured wave characteristics are plotted in Fig. 4. The data measured in the stormy days during the second stage, were found to be more irregular than the first stage. Generally, four stormy periods recognized in the second stage of field investigations are during days: 11$13,30-31,37-45$, and 53-60. Based on the inspection of the measured data in the second stage, the high-order wave height at the entrance of the port can be categorized as long waves with about 24 to 44 seconds period, and as short waves with about 5.5 to 15.2 seconds period. This is generally similar to the main results obtained during the first stage of measurements. It seems that the non-desirable water surface fluctuations may be caused by one of the two categorized high-order incident waves: short waves with low order period, or long waves with high order period. From a comparative analysis of the measured data during both the stages, it can be concluded that the short waves recorded at WD-4 station are the main swell waves with the same periods as those recorded at the seaward wave stations WD-1 to WD-3. But the long waves recorded at WD-4 are mainly caused by the breaking of high-amplitude incident waves. So they have a large period relative to the corresponding waves recorded at seaward wave gauges. It seems that the long-period waves are caused by energy transfer from the breaking wave into the water surface near the mouth of the port. This phenomenon is commonly mentioned as surf beat. 
Table 2. Significant wave height (Hs) and up-zero crossing period (Ts) recorded in the 1st stage field measurements at four seaward wave gauges, italic and bold values are described in the text.

\begin{tabular}{|c|c|c|c|c|c|c|c|c|c|c|c|c|c|c|c|c|c|}
\hline \multirow{2}{*}{$\begin{array}{l}\text { Time } \\
\text { (day) }\end{array}$} & \multicolumn{4}{|c|}{$\mathrm{Hs}(\mathrm{m})$} & \multicolumn{4}{|c|}{ Ts (s) } & \multirow{2}{*}{$\begin{array}{l}\text { Time } \\
\text { (day) }\end{array}$} & \multicolumn{4}{|c|}{$\mathrm{Hs}(\mathrm{m})$} & \multicolumn{4}{|c|}{ Ts (s) } \\
\hline & WD1 & WD2 & WD3 & WD4 & WD1 & WD2 & WD3 & WD4 & & WD1 & WD2 & WD3 & WD4 & WD1 & WD2 & WD3 & WD4 \\
\hline 1 & 0.21 & 0.22 & 0.20 & 0.15 & 7.21 & 6.07 & 6.76 & 6.22 & 31 & 1.02 & 1.13 & 0.97 & 1.14 & 13.23 & 13.61 & 10.69 & 14.22 \\
\hline 2 & 0.33 & 0.31 & 0.25 & 0.21 & 6.25 & 6.88 & 8.37 & 5.81 & 32 & 0.31 & 0.30 & 0.35 & 0.41 & 9.06 & 8.71 & 10.07 & 8.11 \\
\hline 3 & 0.24 & 0.18 & 0.23 & 0.23 & 6.09 & 6.25 & 7.60 & 6.11 & 33 & 0.54 & 0.57 & 0.52 & 0.62 & 7.78 & 7.19 & 6.32 & 8.24 \\
\hline 4 & 0.11 & 0.10 & 0.08 & 0.19 & 6.69 & 6.65 & 5.34 & 5.71 & 34 & 0.71 & 0.68 & 0.77 & 0.81 & 10.57 & 9.34 & 10.16 & 9.56 \\
\hline 5 & 0.53 & 0.51 & 0.55 & 0.59 & 7.14 & 6.06 & 6.13 & 8.19 & 35 & 0.62 & 0.64 & 0.57 & 0.83 & 12.09 & 13.41 & 13.25 & 10.35 \\
\hline 6 & 0.65 & 0.61 & 0.58 & 0.69 & 7.32 & 7.39 & 6.87 & 9.09 & 36 & 0.42 & 0.41 & 0.38 & 0.62 & 9.54 & 9.60 & 8.96 & 8.71 \\
\hline 7 & 0.92 & 0.93 & 0.98 & 1.11 & 8.26 & 8.24 & 7.43 & 7.26 & 37 & 0.31 & 0.32 & 0.31 & 0.41 & 5.60 & 5.89 & 6.63 & 7.93 \\
\hline 8 & 1.21 & 1.35 & 1.30 & 1.31 & 6.48 & 5.29 & 6.18 & 7.38 & 38 & 0.42 & 0.44 & 0.45 & 0.52 & 9.77 & 7.38 & 6.84 & 9.23 \\
\hline 9 & 1.11 & 1.29 & 0.86 & 1.22 & 9.51 & 9.51 & 10.06 & 8.37 & 39 & 0.61 & 0.59 & 0.64 & 0.73 & 9.44 & 10.70 & 11.92 & 10.23 \\
\hline 10 & 0.85 & 0.83 & 0.73 & 1.01 & 9.31 & 7.62 & 6.62 & 9.05 & 40 & 0.84 & 0.76 & 0.77 & 0.94 & 13.47 & 16.55 & 17.85 & 11.34 \\
\hline 11 & 0.92 & 0.81 & 0.80 & 1.02 & 7.97 & 9.04 & 10.28 & 7.51 & 41 & 0.87 & 0.85 & 0.80 & 1.03 & 12.07 & 12.61 & 9.06 & 11.01 \\
\hline 12 & 1.11 & 1.08 & 1.41 & 1.03 & 5.91 & 5.97 & 7.92 & 8.16 & 42 & 0.39 & 0.38 & 0.36 & 0.45 & 8.00 & 6.33 & 5.74 & 8.11 \\
\hline 13 & 0.66 & 0.61 & 0.64 & 0.52 & 9.53 & 11.24 & 11.79 & 8.19 & 43 & 0.68 & 0.75 & 0.76 & 0.77 & 6.61 & 6.46 & 5.95 & 8.37 \\
\hline 14 & 0.32 & 0.30 & 0.27 & 0.44 & 9.86 & 8.86 & 9.53 & 7.85 & 44 & 0.22 & 0.19 & 0.17 & 0.32 & 9.85 & 11.20 & 11.73 & 9.04 \\
\hline 15 & 0.23 & 0.18 & 0.22 & 0.35 & 8.74 & 10.14 & 10.10 & 6.92 & 45 & 0.65 & 0.65 & 0.59 & 0.71 & 5.96 & 5.53 & 6.19 & 8.16 \\
\hline 16 & 0.14 & 0.10 & 0.10 & 0.26 & 4.97 & 5.56 & 6.93 & 5.86 & 46 & 0.95 & 0.95 & 0.94 & 1.05 & 8.00 & 8.03 & 10.30 & 8.33 \\
\hline 17 & 0.31 & 0.28 & 0.33 & 0.44 & 7.20 & 8.14 & 6.79 & 8.24 & 47 & 0.84 & 0.84 & 0.89 & 1.01 & 8.24 & 8.57 & 7.48 & 9.52 \\
\hline 18 & 0.22 & 0.22 & 0.26 & 0.31 & 7.15 & 7.67 & 8.41 & 7.29 & 48 & 1.41 & 1.24 & 1.37 & 1.51 & 13.35 & 13.73 & 15.92 & 11.91 \\
\hline 19 & 0.14 & 0.10 & 0.10 & 0.26 & 6.56 & 7.01 & 7.02 & 5.89 & 49 & 1.62 & 1.61 & 1.61 & 1.73 & 12.18 & 13.63 & 15.59 & 12.52 \\
\hline 20 & 0.34 & 0.32 & 0.37 & 0.34 & 8.74 & 7.63 & 8.31 & 9.08 & 50 & 1.94 & 1.91 & 1.60 & 1.11 & 9.12 & 9.84 & 7.58 & 35.07 \\
\hline 21 & 0.39 & 0.37 & 0.48 & 0.52 & 9.31 & 8.43 & 7.09 & 9.47 & 51 & 2.31 & 2.20 & 2.69 & 1.32 & 10.25 & 11.24 & 13.21 & 41.19 \\
\hline 22 & 0.19 & 0.22 & 0.14 & 0.31 & 8.22 & 6.24 & 6.00 & 7.81 & 52 & 2.92 & 2.68 & 3.52 & 1.24 & 12.19 & 15.26 & 13.82 & 39.17 \\
\hline 23 & 0.62 & 0.62 & 0.70 & 0.71 & 9.15 & 8.66 & 7.83 & 8.32 & 53 & 2.32 & 2.05 & 2.72 & 1.33 & 14.23 & 17.04 & 18.77 & 46.18 \\
\hline 24 & 0.88 & 0.99 & 0.85 & 0.97 & 7.99 & 8.21 & 8.26 & 8.38 & 54 & 2.01 & 1.77 & 1.52 & 1.12 & 10.94 & 11.32 & 12.39 & $\begin{array}{r}37.12 \\
\end{array}$ \\
\hline 25 & 1.51 & 1.54 & 1.72 & 1.02 & 8.31 & 7.38 & 7.64 & 27.20 & 55 & 1.51 & 1.32 & 1.60 & 0.92 & 8.75 & 8.85 & 9.55 & 35.62 \\
\hline 26 & 1.91 & $\begin{array}{ll}1.78 \\
\end{array}$ & 1.89 & 1.11 & 9.42 & 10.88 & 12.10 & 28.31 & 56 & 1.02 & 0.95 & 1.08 & 1.13 & 10.06 & 9.55 & 12.31 & 13.14 \\
\hline 27 & 2.41 & 2.32 & 2.25 & 1.18 & 9.83 & 8.44 & 9.46 & 32.33 & 57 & 1.04 & 1.10 & 1.00 & 1.09 & 12.08 & 13.41 & 17.06 & 11.91 \\
\hline 28 & 3.12 & 3.29 & 2.87 & 1.15 & \begin{tabular}{|l|l|}
9.61 \\
\end{tabular} & 9.31 & 10.04 & 31.23 & 58 & 0.31 & 0.29 & 0.26 & 0.52 & 9.66 & 11.59 & 9.44 & 8.07 \\
\hline 29 & 3.31 & 3.04 & 3.54 & 1.25 & 10.23 & 9.93 & 10.53 & 35.61 & 59 & 0.29 & 0.32 & 0.39 & 0.41 & 7.95 & 7.57 & 7.51 & 7.89 \\
\hline 30 & 1.94 & 1.97 & 2.16 & 1.05 & 9.72 & 7.64 & 8.33 & 31.28 & 60 & 0.29 & 0.33 & 0.38 & 0.42 & 7.82 & 7.58 & 7.49 & 7.92 \\
\hline
\end{tabular}

Table 3. Significant wave height (Hs) and up-zero crossing period (Ts) recorded in the $2^{\text {nd }}$ stage field measurements at four seaward wave gauges, italic and bold values are described in the text.

\begin{tabular}{|c|c|c|c|c|c|c|c|c|c|c|c|c|c|c|c|c|c|}
\hline $\begin{array}{l}\text { ime } \\
\text { (day) }\end{array}$ & \multicolumn{4}{|c|}{$\mathrm{Hs}(\mathrm{m})$} & \multicolumn{4}{|c|}{ Ts (s) } & $\begin{array}{l}\text { Time } \\
\text { (day) }\end{array}$ & \multicolumn{4}{|c|}{$\mathrm{Hs}(\mathrm{m})$} & \multicolumn{4}{|c|}{ Ts (s) } \\
\hline 1 & 0.82 & 0.74 & 0.77 & 0.85 & 6.20 & 10.38 & 14.54 & 4.90 & 31 & 1.16 & 1.16 & 0.91 & 1.20 & 11.82 & 11.56 & 17.41 & 15.26 \\
\hline 2 & 1.10 & 1.08 & 1.29 & 0.91 & 4.19 & 5.14 & 10.57 & 9.96 & 32 & 0.39 & 0.32 & 0.44 & 0.48 & 9.78 & 6.86 & 6.68 & 8.53 \\
\hline 3 & 0.71 & 0.59 & 0.63 & 0.43 & 9.88 & 14.34 & 14.00 & 9.78 & 33 & 0.19 & 0.21 & 0.16 & 0.30 & 8.61 & 7.31 & 4.88 & 5.99 \\
\hline 5 & 0.20 & 0.17 & 0.23 & 0.33 & 8.66 & 12.17 & 10.47 & 8.12 & 35 & 0.84 & 0.87 & 0.83 & 1.03 & 8.27 & 9.22 & 8.11 & 8.70 \\
\hline 6 & 0.16 & 0.09 & 0.09 & 0.26 & 6.14 & 5.29 & 5.44 & 6.99 & 36 & 1.33 & 1.63 & 1.76 & 0.98 & 8.38 & 9.72 & 9.31 & 8.71 \\
\hline 7 & 0.34 & 0.24 & 0.32 & 0.45 & 5.88 & 7.85 & 6.35 & 9.99 & 37 & 3.12 & 3.04 & 3.64 & 0.96 & 7.09 & 10.53 & 14.57 & 30.16 \\
\hline 8 & 0.21 & 0.20 & 0.26 & 0.29 & 8.17 & 4.43 & 7.99 & 8.40 & 38 & 1.69 & 1.68 & 1.69 & 1.07 & 10.32 & 6.77 & 8.10 & 40.23 \\
\hline 11 & 1.65 & 1.60 & 2.02 & 1.04 & 10.22 & 11.61 & 10.66 & 24.62 & 41 & 0.27 & 0.28 & 0.36 & 0.39 & 9.84 & 10.00 & 10.69 & 8.54 \\
\hline 12 & 2.43 & 2.42 & 2.01 & 1.10 & 8.28 & 8.78 & 11.32 & 33.94 & 42 & 2.33 & 2.31 & 2.93 & 1.29 & 16.59 & 23.15 & 19.50 & 31.25 \\
\hline 13 & 3.20 & 2.68 & 2.98 & 0.97 & 10.10 & 6.84 & 13.95 & 38.85 & 43 & 2.08 & 1.64 & 1.54 & 1.08 & 12.93 & 14.79 & 14.16 & 43.24 \\
\hline 14 & 0.53 & 0.58 & 0.60 & 0.72 & 7.85 & 8.83 & 8.76 & 8.75 & 44 & 0.94 & 1.02 & 1.01 & 1.20 & 12.19 & 14.73 & 9.27 & 13.83 \\
\hline 15 & 0.77 & 0.73 & 0.73 & 0.80 & 14.41 & 17.95 & 19.12 & 12.01 & 45 & 0.77 & 0.84 & 0.67 & 1.12 & 12.71 & 14.54 & 8.78 & 12.45 \\
\hline 16 & 0.49 & 0.51 & 0.49 & 0.53 & 9.94 & $\begin{array}{l}6.83 \\
\end{array}$ & $\begin{array}{l}8.91 \\
\end{array}$ & 5.14 & 46 & 0.39 & 0.36 & 0.36 & 0.39 & 11.26 & 8.12 & 7.15 & 6.27 \\
\hline 22 & 0.29 & 0.27 & 0.22 & 0.44 & 11.23 & 10.76 & 6.81 & 8.11 & 52 & 0.78 & 0.70 & 0.79 & 0.78 & 8.13 & 9.37 & 7.94 & 10.57 \\
\hline 23 & 0.26 & 0.33 & 0.40 & 0.39 & 6.35 & 5.47 & 10.94 & 10.50 & 53 & 1.11 & 1.06 & 1.19 & 1.19 & 12.46 & 17.59 & 11.31 & 9.72 \\
\hline 24 & 0.18 & 0.21 & 0.18 & 0.13 & 6.61 & 4.89 & 4.78 & 6.14 & 54 & 1.03 & 1.09 & 1.19 & 1.22 & 10.15 & 14.00 & 18.92 & 12.23 \\
\hline 25 & 0.33 & 0.26 & 0.24 & 0.22 & 5.16 & 5.92 & 9.13 & 7.76 & 55 & 0.52 & 0.62 & 0.52 & 0.67 & 7.45 & 7.36 & 5.72 & 6.09 \\
\hline 26 & 0.20 & 0.15 & 0.23 & 0.21 & 5.99 & 8.35 & 6.39 & 4.36 & 56 & 0.87 & 0.88 & 0.96 & 0.92 & 8.51 & 9.96 & 9.38 & 9.04 \\
\hline 27 & 0.09 & 0.11 & 0.09 & 0.18 & 6.25 & 7.89 & 5.08 & 5.76 & 57 & 1.09 & 1.13 & 1.11 & 1.09 & 4.42 & 4.32 & 7.42 & 5.47 \\
\hline 28 & 0.54 & 0.47 & 0.49 & 0.61 & 7.51 & 5.31 & 6.45 & 7.32 & 58 & 0.93 & 1.16 & 0.75 & 1.26 & 10.08 & 5.61 & 10.41 & 6.72 \\
\hline 29 & 1.52 & 1.08 & 1.53 & 0.88 & 6.58 & 11.94 & 7.89 & 23.11 & 59 & 0.76 & 0.78 & 0.67 & 0.90 & 6.93 & 9.27 & 6.61 & 12.06 \\
\hline 30 & 0.89 & 0.86 & 0.99 & 1.09 & 8.53 & 9.20 & 10.65 & 15.21 & 60 & 1.16 & 1.16 & 0.91 & 1.20 & 11.82 & 11.56 & 17.41 & 7.26 \\
\hline
\end{tabular}




\section{CONCLUSION}

Field measurements have been carried out to investigate the surf beat negative effects on the tranquility of Anzali port located to the southwest of the Caspian Sea. The water surface time series were measured at two 60-days stages and the significant water wave characteristics were captured.

The measured data were investigated to recognize the main source of non-tranquilities of the port. Based on the preliminary investigations on the measured data, it was concluded that the high-order wave height at the entrance of the port can be categorized as long waves with about 24 to $44 \mathrm{~s}$ period, and as short waves with about 5.5 to 15.2 seconds period. The non-desirable water surface fluctuations can be caused by one of the two categorized high-order incident waves: (i) short waves directly penetrated into the port and (ii) infra-gravity long waves with low order frequency due to surf beat effects.

Comparing the measured data recorded at the entrance of the port (Station WD-4) and in-basin recording station, it was concluded that the major negative effects on tranquility of the port is caused by infra-gravity low frequency waves. It is also concluded that the surf beat waves with a frequency range of $0.015-0.025 \mathrm{~Hz}$ caused by wave breaking near the entrance of the port are the main source of undesirable standing waves and non-tranquilities in Anzali Port.

\section{ACKNOWLEDGEMENT}

The authors gratefully acknowledge the technical supports of Water Research Institute (WRI) of Islamic Republic of Iran. All of the staffs of field investigation dept. of WRI are appreciated. Mr. A. Pourmandi as the head of this department is especially thanked.

\section{REFERENCES}

Badiee, P. Bohluli, A. and Zaker, H., 2004. Numerical modeling of penetration of long waves into the Anzali port in Iran. International Conference on Coasts, Ports, and Marine Structures, ICOPMAS, Tehran 27-29 November 2004.

Baldock, T.E. Huntley, D.A. Bird, P.A.D. O'Hare, T.J. and Bullock, G.N., 2000. Breakpoint generated surf beat induced by bichromatic wave groups. Journal of Coastal Engineering, 39, pp. 213-242.
Baldck T.E. and O'Hare T.J., 2004. Energy transfer and dissipation during surf beat conditions. Proc. of 29th Conference on Coastal Engineering, Lisbon, Portugal, 19-24 September 2004.

Ciriano, Y. Coco, G. Bryan, K.R. and Elgar, S., 2005. Field observations of swash zone infragravity motions and beach cusp formation. Journal of Geophysical Research, 110, C02018, DOI: 10.1029/2004JC002485.

Dong, G. Ma, X. Xu, J., 2008. Experimental study of surf beat generated on a submerged sill. Proc. of the 8th ISOPE Pacific and Asia Offshore Mechanics Symposium, Bangkok, Thailand, 10-14 November 2008.

Fujinawa, Y., 1979. Some properties of surf beats. Journal of the Oceanographical Society of Japan, 35, pp. 9-25.

Guza, R.T. Thornton, E.B. and Holman, R.A., 1985. Swash on steep and shallow beaches. Proc. of the 19th Conference on Coastal Engineering, ASCE, pp. 708-723.

Henderson, S.M. and Bowen, A.J., 2003. Simulations of dissipative, shore-oblique infragravity waves. Journal of Physical Oceanography, 33, pp. 1722-1732.

Herbers, T.H.C., Elgar, S. and Guza, R.T., 1995. Generation and propagation of infragravity waves. Journal of Geophysical Ressearch, 100(C12), pp. 24, 863-24, 872.

Holland, K.T. Raubenheimer, B. Guza, R.T. and Holman, R.A., 1995. Runup kinematics on a natural beach, Journal of Geophysical Research, 100(C3), pp. 4985-4993.

Janssen, T.T. Battjes, J.A. and Van Dongeren, A.R., 2002. Observation of long waves induced by short wave groups, Journal of Geophysical Research, 108(C8), pp. 3252-3264.

Longuet-Higgins, M.S. and Stewart, R.W., 1964. Radiation stress in water waves: A physical discussion with applications. Deep Sea Research, 11, pp. 529-562.

Mei, C.C. and Agnon, Y., 1989. Long-period oscillations in a harbor induced by incident short waves. Journal of Fluid Mechanics, 208, pp. 595-608.

Schaffer, H.A., 1993. Infragravity waves induced by short wave groups. Journal of Fluid Mechanics, 247, pp. 551-558.

Symonds, G. Huntley, D.A. and Bowen, A.J, 1982. Two dimensional surf beat: Long wave generation by a timevarying breakpoint. Journal of Geophysical Research, 87, pp. 492-498.

Smallman, J.V. and Cooper, A.J., 1989. Mathematical model for set-down in harbor. Journal of Coastal Engineering, 13, pp. 247-261.

Smith G.G. and Mocke, G.P., 2002. Interaction between breaking/broken waves and infragravity-scale phenomena to control sediment suspension transport in the surf zone. Marine Geology, 187, pp. 329-345.

Tucker, M. J., 1950. Surf beats: Sea waves of 1 to 5 minute period, Proc. of Royal Society, London, Ser. A, 202, pp. 565-573. 